\title{
Quiet Contributors: The Role of the Arts, Humanities and Social Sciences in Innovation
}

\author{
Jonathan Linton \\ Chair in Operations and Technology Management ${ }^{\mathrm{a}}$; Head of Laboratory ${ }^{\mathrm{b}}$, j.linton@sheffield.ac.uk \\ a School of Management of the University of Sheffield, B067, Conduit Road, S10 1LF, UK \\ ${ }^{b}$ Research Laboratory for Science and Technology Studies of the Institute for Statistical Studies and Economics of \\ Knowledge (ISSEK) of the National Research University Higher School of Economics (NRU HSE), 11 Myasnitskaya str., \\ Moscow 101000, Russian Federation
}

\begin{abstract}
$\mathrm{M}$ any countries are directing their attention toward the support of technological innovation in order to obtain economic and social benefits at home while positioning themselves for high margin, high technology export markets. The under-considered and under-exploited role of arts, humanities and social science in innovation is explored in this study. Examples

of programs and activities in a variety of countries are illustrated. Insight is offered into why the arts, humanities and social sciences are important to the generation of social and economic benefits through innovation. Furthermore, recommendations are provided for better reaping the benefits that the arts, humanities and social science can provide.
\end{abstract}

Keywords: Arts, Humanities and Social Sciences;

technological innovation; social innovation; business model innovation; administrative innovation; organizational innovation; cross-disciplinary collaboration
Citation: Linton J. (2018) Quiet Contributors: The Role of the Arts, Humanities and Social Sciences in Innovation. Foresight and STI Governance, vol. 12, no 3, pp. 6-12.

DOI: 10.17323/2500-2597.2018.3.6.12 


\section{Recognizing the Limited Interplay between Innovation and Technology}

One of the challenges faced by academics and researchers in the arts, humanities and social sciences is the fact that politicians and others do not see these areas as contributors to a healthy and prosperous society. While academics often feel undervalued, calls for massive defunding are not expected, but such cutbacks have appeared in increasingly high levels in some countries. For example, in Japan, a letter from the Minister of Education encouraged universities to take "active steps to abolish [these programs]" leading to changes in the programs by close to half (26 of 60) of all Japanese universities [Jenkins, 2015]. While many stakeholders in the arts, humanities, and social sciences are aware of the lack of recognition [Bullen et al., 2004; Lavoie, 2011; Lundströma, Zhou, 2011; Fri, Savitz, 2014; Gulbrandsen, Aanstad, 2015; Hawkins et al., 2015; Murphy et al., 2016; Turcanu et al., 2016; Teixeira et al., 2017] of these disciplines as a critical part of the innovation system in many jurisdictions, the problem remains. Consequently, this paper addresses the relationship between innovation, the arts, humanities, and social sciences in an effort to assist people in understanding and clarifying the extent and nature of the relationship.

Part of the challenge facing the social sciences, arts, and humanities is a misunderstanding of what innovation is. Innovation is anything new that creates some form of value - often economic, but not always. However, innovation is often pictured as being inherently technological. Consequently, policy makers that wish to encourage innovation often end up only incentivizing technological development. While technology is a major contributor to technological innovation, there are many other types of innovation that are also required to extract value from our world. The various types of innovation include: business model innovation, social innovation, administrative innovation, and organizational innovation (Table 1). All four of these types of innovation relate to a variety of non-technological areas including: anthropology, culture/cross-cultural studies, economics, history, philosophy, political science, psychology, and sociology. Notably, a newer definition of social innovation is currently more widely used than traditional one that is part of the traditional innovation management literature.

Another challenge is finding the appropriate measurement for value creation. The adoption of innovation has often been a popular measure, however, it has severe limitations. Adoption involves tracing the pathway, or diffusion, of an innovation through various individuals, households, and firms until it fully serves the appropriate population [Rogers, 1995]. While adoption is critical in areas such as marketing and sales, it is only one of the necessary steps in the innovation process [Tornatzky, Fleischer, 1990]. Value extraction only happens later on in the process - primarily when the something new (innovation) ceases to be new. Once an innovation is adopted, the implementation process begins. The results of the implementation process govern the extent to which value extraction is successful.

Implementation is the mutual adaptation of the innovation and the adopting party (individual, household, firm) to one another. This adaptation involves changes to the innovation so that it is more suitable [Klein, Sorra, 1996] for utilization by the adopting party. Similarly, the adopting party must modify personal perceptions and practices. This allows the adopter to exploit and capture the potential value associated with the innovation. For technological innovations, this dance of mutual adaptation has technological aspects as well as non-technological features, which will be expounded upon later. Furthermore, in the case of implementing the non-technological forms of innovation, the process of mutual adaptation is completely within the realm of the arts, humanities and social sciences. This includes fields such as, but not limited to, psychology and philosophy.

The implementation process ends either when there has been a successful mutual adaptation of the innovation and adopting unit or the implementation process is discontinued prematurely. In cases of successful adaptation, the innovation becomes part of routine practice and behavior [Yin, 1978, 1992].

Table 1. Definitions of Non-Technological Types of Innovations

\begin{tabular}{|l|l|}
\hline \multicolumn{1}{|c|}{ Types of innovation } & \multicolumn{1}{c|}{ Definition } \\
\hline Business model innovation & $\begin{array}{l}\text { New ways of extracting value/making profit from a product - or goods and services - offering. } \\
\text { Examples include: making a profit on consumables or services instead of selling a capital good [Wise, } \\
\text { Baumgartner, 2000]. }\end{array}$ \\
\hline $\begin{array}{l}\text { Social innovation (traditional } \\
\text { academic definition) }\end{array}$ & $\begin{array}{l}\text { Innovation in social systems is required for extracting value from technological innovation. For } \\
\text { example, the patent system is a social innovation intended to encourage people to invent and bring } \\
\text { inventions to the marketplace through a promise to the inventor that they will be rewarded with } \\
\text { monopoly profits for a set period of time enhancing the value extraction opportunities from the } \\
\text { innovation [Linton, 2009]. }\end{array}$ \\
\hline $\begin{array}{l}\text { Social innovation (new } \\
\text { definition) }\end{array}$ & $\begin{array}{l}\text { Innovation that is for the purpose of producing non-economic benefit. Often associated with charitable } \\
\text { or community organizations. The sharing of user innovation [ von Hippel, 2017], such as open source } \\
\text { software [von Krogh, Spaeth, 2007] is included in this category. }\end{array}$ \\
\hline Administrative innovation & $\begin{array}{l}\text { An innovation to a process or system. For example, business process re-engineering [Hammer, Champy, } \\
1993] .\end{array}$ \\
\hline Organizational innovation & $\begin{array}{l}\text { An innovation relating to a change in the structure, interactions, or management of either a group of } \\
\text { people or an organization. }\end{array}$ \\
\hline Source: compiled by the author. & \multicolumn{2}{|l}{} \\
\hline
\end{tabular}


Table 2. Some Issues Related to the Governance of Innovation

\begin{tabular}{|l|l|}
\hline \multicolumn{1}{|c|}{ Issue } & \multicolumn{1}{c|}{ Description } \\
\hline Implementation & $\begin{array}{l}\text { The adopting party modifies perceptions and practices so that the innovation can be utilized for the intended } \\
\text { outcome. }\end{array}$ \\
\hline $\begin{array}{l}\text { Abandonment } \\
\text { decisions }\end{array}$ & $\begin{array}{l}\text { Based upon processes related to various areas of social sciences, arts and humanities - including: economics, } \\
\text { psychology, sociology, culture and philosophy. Regardless of whether the innovation is technological or non- } \\
\text { technological. }\end{array}$ \\
\hline Incorporation & The extraction of benefit is both an art and science as it relates to creativity, learning, and imitation. \\
\hline Source: compiled by the author.
\end{tabular}

Alternatively, abandonment occurs. Abandonment is often an appropriate decision. If an innovation is found unworthy of further effort, there is no reason to complete the resource-consuming mutual adaptation process. Decisions to abandon an innovation are in the realm of social sciences regardless of whether an innovation is technological or non-technological.

If an innovation is not abandoned and becomes part of the routine practice of the adopter (individual, firm or other), the level and nature of the extracted benefit can vary greatly. This is because the routinization does not relate to how efficiently or effectively an innovation has been utilized by the adopter - it simply indicates that the innovation is no longer new and can be expected to stay in use without any additional effort. To understand the extent to which the innovation is used effectively, we must consider incorporation. Incorporation [Zmud, Apple, 1992] is the term used to describe the level of value extracted from an innovation. A skilled user determines how to extract additional value from an innovation not only during the implementation process, but also long afterwards as the user learns more about the innovation and what it is capable of [Barras, 1986]. The processes associated with the extraction of benefit can be derived from the arts and humanities as it relates to creativity, learning, and imitation.

In summary, without the consideration of social sciences, humanities, and the arts, the benefits from technological innovation are at best elusive. To reap these benefits, one must appropriately utilize social sciences, arts, and humanities to understand and manage such issues as implementation, abandonment decisions, and the incorporation of the innovation (Table 2).

\section{Examples of Best Global Practices}

In support of understanding how policy and programs can better allow society to benefit from the economic and social value of innovation, leaders in Science, Technology, and Innovation Policy were interviewed. While there is agreement concerning the importance and interest across the world in the operationalization of the role of arts, humanities, and social sciences in innovation, few countries have interesting experiences in this arena. While specific examples discussed here relate to Canada, Japan, Singapore, and the United States; discussions have also occurred with policy makers in Brazil, China, the European Union, India, Israel, Mexico, OECD member countries, Russia, South Africa, and Taiwan. A subset of activities that were discussed by the policy makers are now considered to help make analysts, policy makers, and other stakeholders more aware of the opportunities for unleashing innovation based upon the social sciences, arts, and humanities. This not only supports following best practices, but also helps to offer insights into possible other future directions.

\section{Digitization and humanities}

Digitization has created many opportunities for the arts and humanities. The internet gave artists the opportunity to disintermediate the existing distribution channels. This allowed them to reach larger audiences and reduced their dependence on intermediaries and brokers that controlled access to markets and used their position to extract most of the value associated with the artistic content. Digitization offers many other opportunities. In smaller economies - such as Singapore - there is experimentation with interdisciplinary labs ${ }^{1}$. The Social Science and Humanities Research Council in Canada was an early aggressive pursuer of the digitization of the humanities ${ }^{2}$.

\section{Foresight activities}

A number of countries engage in foresight activities to provide insight into how the world may look in the future. While the developed potential future scenarios always involve advancements in technology, the focus is on how society may apply, work with, and relate to the new technology and the evolving environment. For example, the Russian government has placed a strong emphasis on how science and technology are intended to support future social goals by providing benefits that are both economic and non-economic [Ponomarev, Dezhina, 2016; Gokhberg, Sokolov, 2017; Gokhberg et al., 2017]. Foresight

\footnotetext{
See, for example, https://www.create.edu.sg/about-create/research-centres/smart, accessed 22.04.2018

${ }^{2}$ For details see: https://www.ssrc.org/programs/view/digital-culture/, accessed 22.04.2018.
} 
activities can range from asking technical experts when they feel certain goals will be achieved to a consideration of the presence or absence of resources that are likely to be needed in the future. For each scenario, consideration is given to the probable societal needs and adaptations. The results identify the sorts of activities that will be required and/or advisable for the preparation for possible future states, for example: new policies and regulations in response to technological advances that have not yet occurred.

\section{Grand challenge approach}

While numerous funding agencies are calling for proposals to meet the global grand challenges that are listed by the United Nations and other international organizations, these calls typically focus on technical solutions. Such calls should be structured in a manner that embraces the interaction between the challenges and society. When society is at the center of the grand challenges, the focus upon and importance of arts, humanities, and social sciences rapidly increases, while technological solutions take a supporting role. For example, there is a program focused on ageing society in Japan supported by NISTEP (National Institute of Science and Technology Policy). This program is focused upon the rapid demographical shift in the age of the Japanese population and the impact that ageing will have on society and its structure. NISTEP has departed from considering the traditional approach of moving elderly people to new accommodation that is specifically designed for geriatric living and/or relying upon family members to act as caregivers. Instead, several sites - villages - have been selected, while the NISTEP study assesses and experiments with what is required in terms of modifications to the home and village infrastructure to provide the ageing residents of these communities the opportunity to continue living independently in their own homes. This not only involves overcoming physical limitations in the household but also considers what else is needed within the community for a happy and healthy lifestyle [NISTEP, 2017].

\section{Government as the lead adopter}

While some governments have a policy to only adopt proven products, others use their purchasing power to encourage the development and diffusion of innovations. Because the United States Small Business Innovation Research (SBIR) and Small Business Technology TRansfer (STTR) programs are so well known and documented, this subject is only briefly mentioned here. What is important to recognize is that many countries adopt the cautious responsible steward approach to government purchasing. In this case, only products that have been proven by others are considered for purchase - for many products this means that domestic products must first be adopted by another country's government. By putting the development of innovation in one's own country at a disadvantage through either policy or habit, governments force innovators to prove their innovation in a foreign country. Often this results in a permanent relocation of innovators outside of their home country.

\section{Elevating awareness of administrative innovation}

The Innovations in American Government Program ${ }^{3}$ encourages the awareness, celebration, and diffusion of innovation at all levels of government. The program not only rewards innovation and encourages its diffusion but raises the level of understanding that high impact/high value innovation often occurs independently of technological advancements.

\section{Programmatic requirement for Social Science and Humanities}

While technological innovation always contains an arts, humanities, and social sciences component, this element is often not specifically addressed by research funding. For example, funding has focused on moving science to technology and technology from low Technology Readiness Levels (TRLs) to higher TRLs (Table 3). For example, there is a separate guide on what constitutes technological readiness in autonomous vehicles (Table 4).

However, these guidelines are based upon the assumption that autonomous transport in the future will be identical with existing transport systems - a highly unlikely situation. While models of how to address these challenges are limited, insights on how to take into account societal impacts can be gained from the Genome Canada program ${ }^{4}$.

Genome Canada's intention is to fund translational research on genetics that leads to products. While Genome Canada gives contracts as opposed to grants, academic researchers in Canada often do not distinguish between research that is funded for knowledge creation (grants) and commercialization (contracts). Genome Canada requires that $10 \%$ of each contract is dedicated to non-technical work related to translational research - referred to as GE3LS (pronounced gels). GE3LS (Genomics and its Ethical, Economic, Environmental, Legal, and Social Aspects) funds must address the interaction of genetic research and society. The initial focus of GE3LS grants was upon medical ethics and economics. This has gradually widened to include other areas with a greater focus upon value extraction: for example, management and law. Typically, the GE3LS partner is focused on a specific field like medical ethics. In

\footnotetext{
${ }^{3}$ Available at: https://ash.harvard.edu/innovations-american-government-awards, accessed 15.03.2018.

${ }^{4}$ Available at: https://www.genomecanada.ca/, accessed 15.03.2018.
} 
Table 3. The European Union Definition of Technological Readiness Levels (TRLs)

\begin{tabular}{|c|l|}
\hline $\begin{array}{c}\text { Technology Readiness } \\
\text { Level }\end{array}$ & \multicolumn{1}{c|}{ Description } \\
\hline TRL 1 & Basic principles observed \\
\hline TRL 2 & Technology concept formulated \\
\hline TRL 3 & Experimental proof of concept \\
\hline TRL 4 & Technology validated in lab \\
\hline TRL 5 & Technology validated in the relevant environment \\
\hline TRL 6 & Technology demonstrated in the relevant environment \\
\hline TRL 7 & System prototype demonstration in operational environment \\
\hline TRL 8 & System complete and qualified \\
\hline TRL 9 & $\begin{array}{l}\text { Actual system proven in operational environment (competitive manufacturing in the case of key enabling } \\
\text { technologies; or in space) }\end{array}$ \\
\hline $\begin{array}{l}\text { Note: }{ }^{*}-\text { industrially relevant environment in the case of key enabling technologies. } \\
\text { Source: [European Commission, 2014]. }\end{array}$ \\
\hline
\end{tabular}

some cases, the GE3LS and scientific components are completely independent of one another and the teams only come together for meetings with the funding agency. On other occasions, there is greater and greater interaction between the separate research groups over time. When this greater interaction occurs, it is recognized that in order to translate research into practice, this will require more than $10 \%$ of the funding and a wider range of non-technical specialists (i.e., there is anecdotal evidence of scientists looking for more involvement with different types of people in the arts, humanities, and social sciences). However, this small forced interaction provides a useful starting point for addressing a complex problem. While requiring technological projects to have a non-technical component-as is the case with the GE ${ }^{3} \mathrm{LS}$ program-is not always successful, it ensures that there is some consideration and activity related to the interaction between technology and society. This is the preferred starting point. Cross-disciplinary interaction requires academic researchers that are unaccustomed to working with academics from very different fields to interact with one another. It also challenges universities, as these organizations are often ill equipped for developing and building interdisciplinary teams either with a bottom-up or topdown approach. Similarly, the internal university structure is often ill suited for supporting the funding required for the interaction between researchers in different departments and faculties. As Genome Canada contracts involve millions of Canadian dollars in a single contract, a $\mathrm{GE}^{3} \mathrm{LS}$ contract is worth hundreds of thousands of dollars to a Co-Principal Investigator based in an arts, humanities, or social sciences department, making it among the largest grants available to Canadian researchers in these faculties. As the rate of commercialization has been lower than desired and the coordination between technical and $\mathrm{GE}^{3} \mathrm{LS}$ researchers has not been as seamless as hoped, there is interest in improving the current model.

\section{Implications for Policy and Programs to Support Better Value Extraction from Innovation}

Having outlined some programs that offer different approaches to the integration of arts, humanities, and social sciences into the innovation agenda, the implications for encouraging greater levels of innovation are considered.

\begin{tabular}{|c|c|c|c|}
\hline $\begin{array}{l}\text { SAE } \\
\text { Level }\end{array}$ & Name & \multicolumn{2}{|c|}{ Narrative definition } \\
\hline 0 & No Automation & \multicolumn{2}{|c|}{$\begin{array}{l}\text { The full-time performance by the human driver of all aspects of the dynamic driving task, even when } \\
\text { «enhanced by warning or intervention systems» }\end{array}$} \\
\hline 1 & Drive Assistance & $\begin{array}{l}\text { The driving mode-specific execution by a driver assistance } \\
\text { system of «either steering or acceleration/deceleration» }\end{array}$ & \multirow{2}{*}{$\begin{array}{l}\text { using information about the driving } \\
\text { environment and with the expectation } \\
\text { that the human driver performs all } \\
\text { remaining aspects of the dynamic } \\
\text { driving task }\end{array}$} \\
\hline 2 & $\begin{array}{l}\text { Partial } \\
\text { Automation }\end{array}$ & $\begin{array}{l}\text { The driving mode-specific execution by one or more driver } \\
\text { assistance systems of both steering and acceleration/deceleration }\end{array}$ & \\
\hline 3 & $\begin{array}{l}\text { Conditional } \\
\text { Automation }\end{array}$ & \multirow{3}{*}{$\begin{array}{l}\text { The driving mode-specific performance by an automated } \\
\text { driving system of all aspects of the dynamic driving task }\end{array}$} & $\begin{array}{l}\text { with the expectation that the human } \\
\text { driver will respond appropriately to } \\
\text { a request to intervene }\end{array}$ \\
\hline 4 & High Automation & & $\begin{array}{l}\text { even if a human driver does not respond } \\
\text { appropriately to a request to intervene }\end{array}$ \\
\hline 5 & Full Automation & & $\begin{array}{l}\text { under all roadway and environmental } \\
\text { conditions that can be managed by } \\
\text { a human driver }\end{array}$ \\
\hline
\end{tabular}


Table 5. Non-Technological Innovations as Sources of Value Extraction

\begin{tabular}{|l|l|}
\hline \multicolumn{1}{|c|}{ Type of innovation } & \multicolumn{1}{c|}{ Means of value extraction } \\
\hline Social innovation & Allows and/or enhances the possibility of value extraction from technological innovation. \\
\hline Business innovation & Allows one to extract value that would otherwise be lost due to market externalities \\
\hline Administrative innovation & Changes some element of existing business processes and/or systems \\
\hline Organizational innovation & Creates value by changing the structure of social systems such as groups or organizations \\
\hline Source: compiled by the author. & \\
\hline
\end{tabular}

Above all, it is necessary to raise awareness that innovation is most often not technological, by supporting the programs that illustrate the importance of relevant dimensions of innovation. Table 5 summarizes the means of value extraction that are inherent to different types of non-technological innovation.

Further, one should focus on extracting value from a technology as opposed to developing a technology. The UK has been characterized as having excellence in science, but not in technology. However, studies of British technology have shown that the UK is successful in producing innovative technology - such as EMI's CT Scanner. While EMI was the developer of a successful product, they lost market share and eventually the entire market to General Electric (GE). GE's focus was on extracting value from the technology and utilizing business model innovation. This strategy allowed GE to catch up and eventually eliminate EMI from the market [Mitchell, 1994]. Perhaps if EMI had been a leader in both technological and business model innovation, they could have fought off GE's competitive challenge.

Finally, it is viable to force interaction - with patience. Researchers are educated, trained, and rewarded for having an intense interest in one specific field of study. Universities, their departments, and faculties are similarly structured, assessed, and rewarded for narrow specialization. Innovation - technological or otherwise - calls for an interdisciplinary focus on problems and/or opportunities. While incentivizing (forcing) technological researchers to work with arts, humanities, and social sciences researchers may seem inefficient, it is worthwhile if there is interest in exploiting technological innovation. Similarly, it is worth incentivizing other forms of translational research (e.g., those involving arts, humanities, and social sciences) to unleash innovation.

Incentivizing the interaction between different fields and faculties should not be limited to research, it should also be encouraged for undergraduate and graduate education. The association of degree programs with specific departments is a major hindrance to the goal of encouraging different specialties (departments) to work with one another in general.

\section{Conclusions}

Historically, innovation has not been the focus of national laboratories or universities in most countries. If innovation is to be a priority, new incentives and approaches are required as innovation requires a blending of expertise from a variety of fields.

The first barrier is a clear understanding of the existence and nature of different types of innovation and how all types of innovation - even technological innovations - rely heavily upon input from the arts, humanities, and social sciences. There is no clear global leader in innovation for the arts, humanities, and social sciences. However, there is recognition that this area is under-developed and offers excellent opportunities for international cooperation.

The three recommendations offered to advocates of innovation are to:

1. Raise awareness about the fact that innovation is most often not technological

2. Focus on extracting value from technology as opposed to developing technology

3. Force interaction across disciplines - but to do so with patience.

This project was supported by the Innovation Caucus, funded by Innovate UK and the Economic and Social Research Council. This article was prepared within the framework of the Basic Research Program at the National Research University Higher School of Economics (HSE) and supported within the framework of subsidy provided by the Russian Academic Excellence Project '5-100'. Finally, a thank you to Linda Xu for the thorough literature review she conducted on the prior academic work at the interface of innovation the arts, humanities and social sciences.

\section{References}

Barras R. (1986) Towards a Theory of Innovation in Services. Research Policy, vol. 15, pp. 161-173.

Bullen E., Robb S., Kenway J. (2004) 'Creative destruction': Knowledge economy policy and the future of the arts and humanities in the academy. Journal of Education Policy, vol. 19, no 1, pp. 3-22. 
European Commission (2014) HORIZON 2020 - Work Programme 2014-2015 (Annex G. Technology Readiness Levels (TRL) as Defined by the Commission Decision C(2014)4995), Brussels: European Commission. Available at: https://ec.europa.eu/research/participants/data/ref/h2020/wp/2014_2015/annexes/h2020-wp1415-annex-gtrl_en.pdf, accessed 15.05.2018.

Fri R.W., Savitz M.L. (2014) Rethinking energy innovation and social science. Energy Research and Social Science, vol. 1, pp. 183-187.

Gokhberg L., Sokolov A. (2017) Technology foresight in Russia in historical evolutionary perspective. Technological Forecasting and Social Change, vol. 119, pp. 256-267.

Gokhberg L., Sokolov A., Chulok A. (2017) Russian S\&T Foresight 2030: Identifying New Drivers of Growth. Foresight, vol. 19, no 5, pp. 441-456.

Gulbrandsen M., Aanstad S. (2015) Is innovation a useful concept for arts and humanities research? Arts and Humanities in Higher Education, vol. 14, no 1, pp. 9-24.

Hammer M., Champy J. (1993) Reengineering the Corporation, Harper Collins: New York.

Hawkins R., Langford C.H., Saunders C. (2015) Assessing the practical application of social knowledge: A survey of six leading Canadian universities. Research Policy, vol. 44, no 1, pp. 83-95.

Jenkins N. (2015) Alarm over huge cuts to humanities and social science at Japanese universities. Time Magazine, September 16. Available at: http://time.com/4035819/japan-university-liberal-arts-humanities-social-sciencescuts/, accessed 17.07.2018.

Klein K.J., Sorra J.S. (1996) The challenge of innovation implementation. Academy of Management Review, vol. 21, no 4, pp. 1055-1080.

Lavoie M. (2011) The role of social scientists in accelerating innovation in regenerative medicine. Review of Policy Research, vol. 28, no 6, pp. 613-630.

Linton J.D. (2009) De-Babelizing the Language of Innovation. Technovation, vol. 29, no 11, pp. 729-737.

Lundströma A., Zhou C. (2011) Promoting innovation based on social sciences and technologies: The prospect of a social innovation park. Innovation, vol. 24, no 1-2, pp. 133-149.

Mitchell W. (1994) Playing leap-frog with Elephants: EMI, Ltd. and CT scanner competition in the 1970s. A Case Study by the University of Michigan Business School. Available at: http://www-personal.umich.edu/ afuah/cases/case4. html, accessed 11.03.2018.

Murphy J., Parry S., Walls J. (2016) The EPSRC's Policy of Responsible Innovation from a Trading Zones Perspective. Minerva, vol. 54, no 2, pp. 151-174.

NISTEP (2017) Efforts aimed at realizing a sustainable aging society and low carbon society (Part 2 - Study on the ideal way of living in the area) // STI Horizon. Vol. 3. № 1. Available at: http://doi.org/10.15108/stih.00070, accessed 15.02.2018.

Ponomarev A., Dezhina I. (2016) Approaches to the formulation of Russia's technological priorities. Foresight and STI Governance, vol. 10, no 1, pp. 7-15.

Rogers E.M. (1995) The Diffusion of Innovations ( $4^{\text {th }}$ ed), New York: Free Press.

SAE (2014) Taxonomy and Definitions for Terms Related to On-Road Motor Vehicle Automated Driving Systems J3016_201401. Available at: https://www.sae.org/standards/content/j3016_201401/, accessed 15.05.2018.

Teixeira A.A.C., Vieira P.C., Abreu A.P. (2017) Sleeping Beauties and their princes in innovation studies. Scientometrics, vol. 110, no 2, pp. 541-580.

Tornatzky L.G., Fleischer M. (1990) The Process of Technological Innovation, Lexington: Lexington Books.

Turcanu C., Schröder J., Meskens G., Perko T., Rossignol N., Carlé B., Hardeman F. (2016) Like a bridge over troubled water - Opening pathways for integrating social sciences and humanities into nuclear research. Journal of Environmental Radioactivity, vol. 153, no 88-96.

von Hippel E. (2017) Free Innovation, Boston MA: MIT Press.

von Krogh G., Spaeth S. (2007) The open source software phenomenon: Characteristics that promote research. Journal of Strategic Information Systems, vol. 16, no 3, pp. 236-253.

Wise R., Baumgartner P. (2000) Go downstream: The new profit imperative in manufacturing. IEEE Engineering Management Review, vol. 28, pp. 89-96.

Yin R.K. (1978) Changing Urban Bureaucracies: How New Practices Become Routinized, Santa Monica, CA: Rand Corporation.

Yin R.K. (1992) Measuring success in AMT implementation using customer-supplier interaction criteria. International Journal of Operations and Production Management, vol. 12, no 10, pp. 34-55.

Zmud R.W., Apple E. (1992) Measuring Technology Incorporation/Infusion. Journal of Product Innovation Management, vol. 9, no 2, pp. 148-155. 